\title{
Effect of Extraction Ethanol Concentration on Antioxidant and Anti-Inflammatory Activity of 30-Year-Old and 120-Year-Old Dangyuja (Citrus maxima (Burm.) Merr.)
}

\author{
Sung-Gyu Lee ${ }^{1, *}$, Dongsup Lee ${ }^{2, *}$ and Hyun Kang ${ }^{1, \uparrow, *}$ \\ ${ }^{1}$ Department of Medical Laboratory Science, College of Health Science, \\ Dankook University, Cheonan-si, Chungnam 31116, Korea \\ ${ }^{2}$ Department of Clinical Laboratory Science, Hyejeon College, Hongseong 32244, Korea
}

\begin{abstract}
Dangyuja (Citrus maxima (Burm.) Merr.) is a native fruit of great economic importance in Jeju island in Korea. To provide experimental evidence for the antioxidant and anti-inflammation properties on extraction ethanol concentration of Dangyuja, 2 cultivars, including 30-year-old and 120-year-old were evaluated. 30-year-old Dangyuja 50\%, 70\% ethanol extracts had the highest polyphenol and flavonoid content, and the strongest 2,2'-azino-bis (3-ethylbenzothiazoline-6sulfonic acid) (ABTS) radical scavenging activity. To investigate the anti-inflammatory activity of Dangyuja ethanol extracts, we used BV-2 microglia cells and induced inflammation using lipopolysaccharide (LPS). Then, we measured levels of inflammatory mediators as nitric oxide (NO). Among the 6 extracts, 30-year-old Dangyuja 50\% ethanol extracts show the highest anti-inflammatory activity. The results suggest that 30 -year-old Dangyuja $50 \%$ ethanol extracts provides significant health benefits and may be used for developing new functional materials.
\end{abstract}

Key Words: Citrus maxima (Burm.) Merr., Extraction condition, ABTS, Polyphenol, NO

Dangyuja (Citrus maxima (Burm.) Merr.), a traditional citrus in Jeju Island, is called Jeju 'Daengyuji', and is one of native Citrus species (Song et al., 1997). Peel of Dangyuja are known to be rich sources of polyphenolic compounds, particularly flavonoids such as naringin, hesperidin, and neohesperidin (Kim et al., 2007; Lee et al., 2006). Flavonoids in Dangyuja have been attracting interest because of their significant bioactivities. The health benefits of Dangyuja, including anticancer, antivirus, antioxidant, and antiinflammatory, have been reported (Kim et al., 2007; Lee et al., 2006; Lim et al., 2006; Lim et al., 2009).

There are many techniques to recover active component from plants, such as ultrasound-assisted extraction, maceration, supercritical fluid extraction, subcritical water extraction, and Soxhlet extraction. However, active component extraction yield and bioactive not only depend on the extraction method but also on the solvent used for extraction. Polar solvents are frequently used for recovering polyphenols from plants (Turkmen et al., 2006). Especially, ethanol has been known as a good solvent for polyphenol extraction and is safe for human consumption (Dai and Mumper, 2010).

The objective of this study was to investigate the effects of ethanol concentration on the extraction of polyphenol and flavonoid from Dangyuja and investigate the antioxidant

Received: May 29, 2020 / Revised: June 25, 2020 / Accepted: June 27, 2020

* Professor

${ }^{\dagger}$ Corresponding author: Hyun Kang. Department of Medical Laboratory Science, College of Health Science, Dankook University, Cheonan-si, Chungnam 31116, Korea.

Tel: +82-41-550-3015, Fax:+82-41-559-7934, e-mail: hkang@dankook.ac.kr

(C) The Korean Society for Biomedical Laboratory Sciences. All rights reserved.

(@) This is an Open Access article distributed under the terms of the Creative Commons Attribution Non-Commercial License (http://creativecommons.org/licenses/by-nc/3.0/) which permits unrestricted non-commercial use, distribution, and reproduction in any medium, provided the original work is properly cited. 


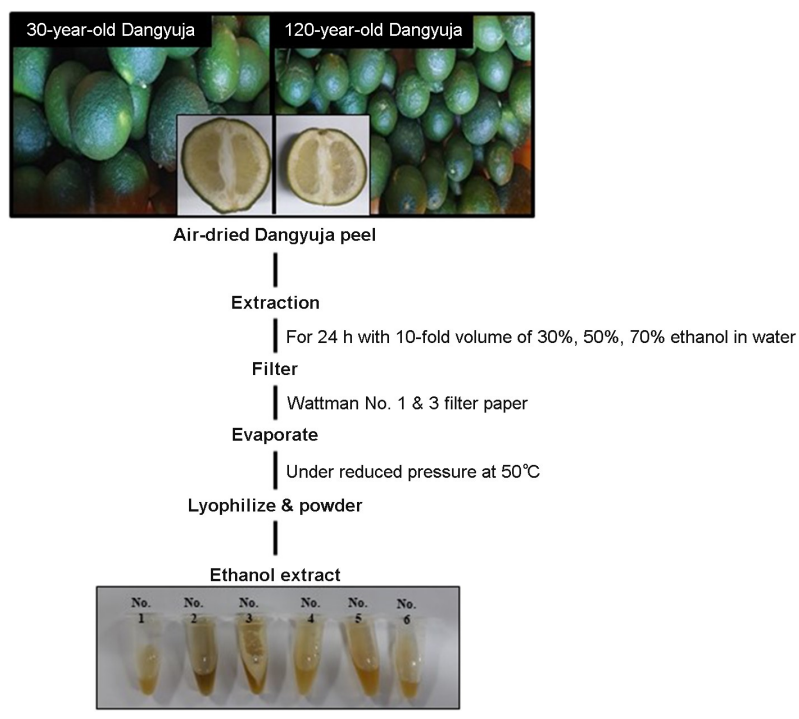

Fig. 1. Schematic diagram for preparation of Dangyuja peel ethanol extracts. No. 1; 30-year-old Dangyuja peel 30\% EtOH extract, No. 2; 30-year-old Dangyuja peel 50\% EtOH extract, No. 3; 30-year-old Dangyuja peel 70\% EtOH extract, No. 4; 120 year-old Dangyuja peel 30\% EtOH extract, No. 5; 120-year-old Dangyuja peel 50\% EtOH extract, No. 6; 120-year-old Dangyuja peel $70 \%$ EtOH extract.

and anti-inflammatory activity of the extracts by in vitro methods.

The Dangyuja 2 cultivars, including 30-year-old and 120year-old used in this study was bought at a Jeju Island. First, Dangyuja peel was separated, air dried at room temperature (RT). It was pulverized using a milling machine and extracted with $30 \%, 50 \%, 70 \%$ ethanol by stirring for $24 \mathrm{~h}$ at RT. The extract was filtered, concentrated with a vacuum rotary evaporator under reduced pressure, and lyophilized (Fig. 1). The yield of Dangyuja extract was calculated by the dry weight ratio of the extract. Yields of $30 \%, 50 \%$, and $70 \%$ ethanol extracts of 30-year-old Dangyuja peel were $22.5 \%$, $25.3 \%$, and $28.1 \%$, respectively. Yields of $30 \%, 50 \%$, and $70 \%$ ethanol extracts from 120-year-old Dangyuja peel were $20.3 \%, 22.6 \%$, and $27.2 \%$, respectively. It was confirmed that the higher the concentration of ethanol, the higher the extraction yield.

To investigate anti-oxidative activities was confirmed using to total polyphenol and flavonoid contents, and ABTS radical scavenging effect. The total polyphenol content was measured by modifying the Folin-Denis (Folin and Denis,
1912) method. After diluting the Dangyuja ethanol extracts to various concentrations, the diluted samples $60 \mu \mathrm{L}$ were dispensed in 96 well-plates. After adding 2-fold diluted Folin reagent and reacting for $3 \mathrm{~min}$, the same amount of $10 \%$ sodium carbonate $\left(\mathrm{Na}_{2} \mathrm{CO}_{3}\right)$ was added and reacted for $1 \mathrm{~h}$ to measure absorbance at $700 \mathrm{~nm}$. The total polyphenol content was calculated based on a standard curve obtain with gallic acid (Sigma Chemical Co., St. Louis, Mo. USA). Total flavonoid content was measured by the method of Nieva Moreno et al. (2000). After diluting the Dangyuja ethanol extracts $(100 \mu \mathrm{L})$ was mixed with $860 \mu \mathrm{L}$ of $80 \%$ ethanol, adding $20 \mu \mathrm{L}$ of $10 \%$ aluminum nitrate and $1 \mathrm{M}$ potassium acetate. The absorbance was then measured at $415 \mathrm{~nm}$ after incubation for $40 \mathrm{~min}$. A standard calibration curve was prepared using Quercetin (Sigma Chemical Co.). The ABTS radical scavenging activity measurement was performed by previously described method (Re et al., 1999). To ABTS radical formation, $14 \mathrm{mM}$ 2,2-azino-bis (3-ethylbenzthiazoline-6-sulfonic acid) (ABTS, Sigma Chemical Co., USA) and $4.9 \mathrm{mM}$ potassium persulfate were mixed at room temperature for $24 \mathrm{~h}$, it was diluted with phosphate buffer saline (PBS, $\mathrm{pH}$ 7.4) so that the absorbance value at $732 \mathrm{~nm}$ was $0.70( \pm 0.02)$. After adding $20 \mu \mathrm{L}$ of sample to $180 \mu \mathrm{L}$ of the diluted solution, it was allowed to stand for exactly 1 minute, and absorbance was measured at $732 \mathrm{~nm}$. All experiments were repeated three times.

To measure the anti-inflammatory activity of the Dangyuja ethanol extracts, we used BV-2 microglia cells and induced inflammation using LPS (Sigma Chemical Co.). BV-2 cells were cultured in RPME1640 (Gibco BRL, NY, USA) supplemented with $10 \%$ fetal bovine serum (FBS; Gibco BRL) and $1 \%$ antibiotic-antimycotic (Gibco BRL) at $37^{\circ} \mathrm{C}$ in a humidified incubator with $5 \% \mathrm{CO}_{2}$. To measure cell viability against Dangyuja ethanol extracts, it was measured by a 3[4,5-Dimethylthiazol-2-yl]-2,5-diphenyl-tetrazolium bromide (MTT) assay. Cells $\left(1 \times 10^{5}\right.$ cell $\left./ \mathrm{mL}\right)$ were dispensed in $100 \mu \mathrm{L}$ in 96 well-plates and cultured in $\mathrm{a}_{2}$ incubator for more than $12 \mathrm{~h}$, and then followed by incubation for $24 \mathrm{~h}$ by treating $100 \mu \mathrm{L}$ of fresh medium and Dangyuja ethanol extracts $(250 \mu \mathrm{g} / \mathrm{mL})$. After $24 \mathrm{~h}, 10 \mu \mathrm{L}$ of MTT $(2.5 \mathrm{mg} /$ $\mathrm{mL}$ ) was added, followed by incubation for $4 \mathrm{~h}$. And then, the culture medium was removed, and $100 \mu \mathrm{L}$ of dimethyl- 
sulfoxide (DMSO) was added to dissolve the generated formazone crystals, and measured at $540 \mathrm{~nm}$ using a microplate reader. Cell viability was expressed as a percentage (\%) compared to the control. The inhibitory effect of nitric oxide (NO) was measured by reacting the $\mathrm{NO}_{2}^{-}$form present in the cell culture with Griess Reagent using the method of Green et al. (1982). BV-2 cells $\left(1 \times 10^{5}\right.$ cell $\left./ \mathrm{mL}\right)$ were cultured in 96-well plates overnight. The cells were treated with Dangyuja ethanol extracts $(250 \mu \mathrm{g} / \mathrm{mL})$ and $100 \mathrm{ng} /$ $\mathrm{mL}$ of lipopolysaccharide (LPS) for $24 \mathrm{~h}$. And then, $100 \mu \mathrm{L}$ of cell culture solution and $100 \mu \mathrm{L}$ of Griess reagent (Sigma Chemical Co.) were mixed and reacted in 96 well-plates for $10 \mathrm{~min}$, and then measured at $540 \mathrm{~nm}$ using a microplate reader.

All statistical analyses were performed using SPSS version 12.0 for Windows (SPSS, Chicago, IL, USA). Values were expressed as mean \pm standard error of the mean (SEM) for $\mathrm{N}=3$. Data were analysis using one-way analysis of variance (ANOVA) and Duncan's multiple-range tests with $P<0.05$ were considered significant.

To determine the antioxidant activity of Dangyuja peel extracted by $30 \%, 50 \%, 70 \%$ ethanol concentration, we first measured polyphenol and flavonoid content. Phenolic compounds have long been known to act on various biologically active, and many studies have been conducted (Ho et al., 2018). Total polyphenol content values were obtained from the calibration curve using gallic acid (Fig. 2A). The total polyphenol content values of the extracts range from 51.54 $\mathrm{mg} / \mathrm{g}$ to $71.96 \mathrm{mg} / \mathrm{g}$ and they decrease in the following order: No. $2(71.96 \mathrm{mg} / \mathrm{g})>$ No. $3(71.54 \mathrm{mg} / \mathrm{g})>$ No. $6(66.23$ $\mathrm{mg} / \mathrm{g})>$ No. $5(65.33 \mathrm{mg} / \mathrm{g})>$ No. $4(61.48 \mathrm{mg} / \mathrm{g})>$ No. 1 $(51.54 \mathrm{mg} / \mathrm{g})$. The total flavonoid content of the extracts was reported in Fig. 2B. Total flavonoid content was calculated using quercetin. The total flavonoid content values of the extracts range from $37.32 \mathrm{mg} / \mathrm{g}$ to $66.74 \mathrm{mg} / \mathrm{g}$ and they decrease in the following order: No. $3(66.74 \mathrm{mg} / \mathrm{g})>$ No. $2(65.24 \mathrm{mg} / \mathrm{g})>$ No. $6(53.67 \mathrm{mg} / \mathrm{g})>$ No. $5(52.12 \mathrm{mg}$ $/ g)>$ No. $4(50.24 \mathrm{mg} / \mathrm{g})>$ No. $1(37.32 \mathrm{mg} / \mathrm{g})$. Based on the results of total polyphenol and flavonoid content, the 30year-old Dangyuja peel is higher than 120-year-old Dangyuja peel, and the best extracting concentration of ethanol was $50 \%$ to $70 \%$. 30-year-old Dangyuja peel $50 \%$ ethanol extract

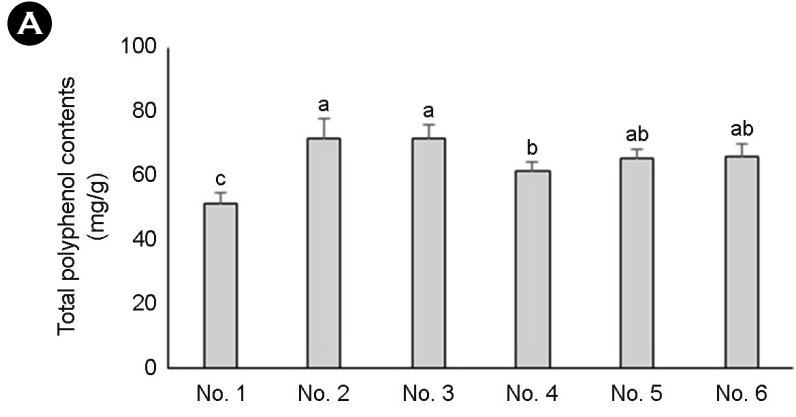

B

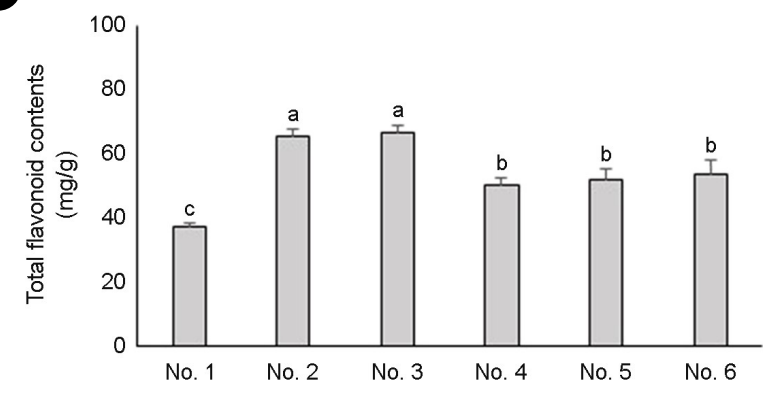

C

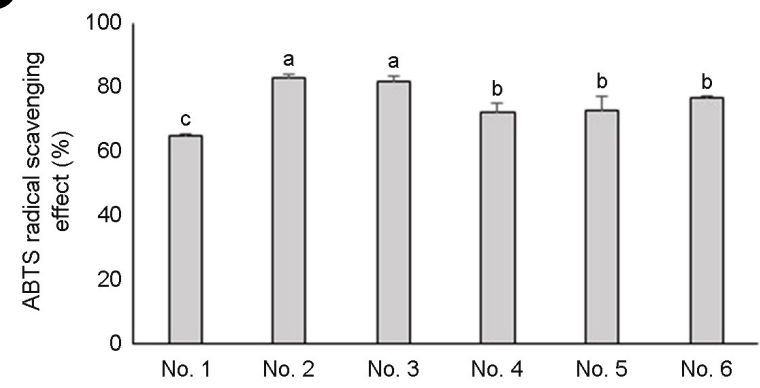

Fig. 2. Antioxidant activity of Dangyuja peel ethanol extracts. (A) Total polyphenol contents; (B) Total flavonoid contents; (C) ABTS radical scavenging effect. ABTS radical treatment extract concentration is $100 \mu \mathrm{g} / \mathrm{mL}$. Data were analysis using one-way analysis of variance (ANOVA) and Duncan's multiple-range tests with $P<0.05$ were considered significant.

also showed the highest ABTS radical scavenging activities (Fig. 2C).

We measured cell viability of BV-2 cells to investigate the cell cytotoxicity of Dangyuja peel extract. Although the survival rate of $90 \%$ or more was showed in almost all extracts, the 120-year-old Dangyuja peel $70 \%$ ethanol extract showed cytotoxicity with a survival rate of $65.32 \%$ (Fig. 3A). To determine the inflammatory activity of Dangyuja peel extract, we measured major inflammatory mediators, nitric oxide (NO). In LPS-induced BV-2 cells, 120-year-old 
A

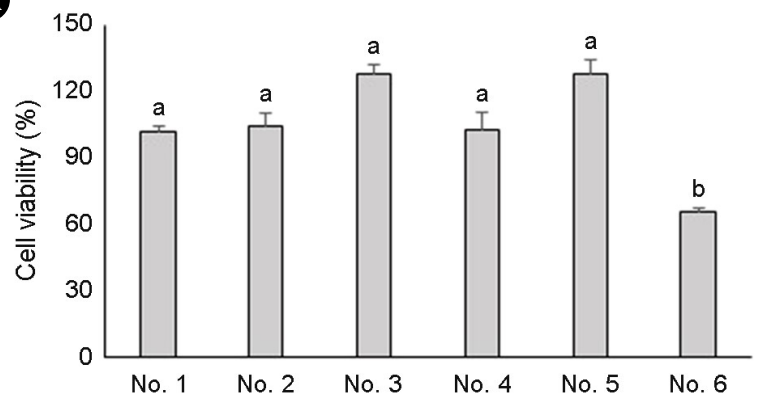

B

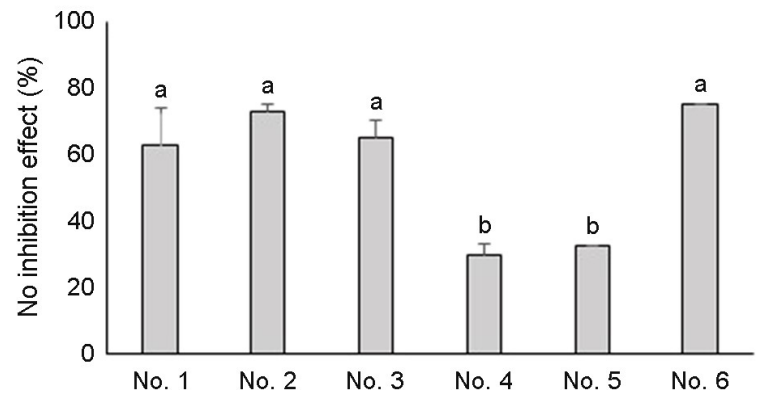

Fig. 3. Cell viability and anti-inflammatory activity of Dangyuja peel ethanol extracts in LPS-induced BV-2 cells. (A) Cell viability was measured using an MTT assay; (B) NO inhibition was represented as \% against control: Inhibition effect $(\%)=\{($ ControlSample)/Control $\} \times 100$. The concentration of the extracts is 250 $\mu \mathrm{g} / \mathrm{mL}$. Data were analysis using one-way analysis of variance (ANOVA) and Duncan's multiple-range tests with $P<0.05$ were considered significant.

Dangyuja peel $70 \%$ ethanol extract showed the best NO inhibition effect, but it is thought to be a result of cytotoxicity. In the extracts except 120-year-old Dangyuja peel 70\% ethanol extract, 30-year-old Dangyuja peel 50\% ethanol extract showed the best NO inhibitory ability (Fig. 3B).

In conclusion, it is clear that 30-year-old Dangyuja peel $50 \%$ ethanol extract gave the highest antioxidant and antiinflammatory in all in vitro assays studied. Therefore, 30year-old Dangyuja 50\% ethanol extracts provides significant health benefits and may be used for developing new functional materials. Also, further research is required that on the separation and purification of active compounds with antioxidant and anti-inflammatory effects are expected.

\section{ACKNOWLEDGEMENT}

This research was supported by the Ministry of Trade, Industry \& Energy MOTIE), Korea Institute for Advance- ment of Technology(KIAT) through the Encouragement Program for The Industries of Economic Cooperation Region (Project Name: Development a functional raw materials and a premium product of improving scalp care cosmetics by regional specialized natural resources/Project Number: P0008627).

\section{CONFLICT OF INTEREST}

The authors declare that there is no conflict of interests regarding the publication this articles.

\section{REFERENCES}

Dai J, Mumper RJ. Plant phenolics: extraction, analysis and their antioxidant and anticancer properties. Molecules. 2010. 15: 7313-7352.

Folin O, Denis W. On phosphotungstic-phosphomolybdic compounds as color reagents. The Journal of Biological Chemistry. 1912. 12: 239-249.

Green LC, Wagner DA, Glogowski J. Analysis of nitrate, and [15N]nitrate in biological fluids. Analytical Biochemistry. 1982. 126: $131-138$.

Ho LH, Ramli NF, Tan TC, Muhamad N, Haron MN. Effect of extraction solvents and drying conditions on total phenolic content and antioxidant properties of water melon rind powder. Sains Malaysiana. 2018. 47: 99-107.

Kim YJ, Moon JY, Kim JH, Kim HG, Kim JH, Cho SK. Effects of mixing method and storage period of Dangyuja-sugar mixture on customer preferences food Dangyuja-tea. Korean Journal of Food Preservation. 2007. 14: 160-164.

Lee HJ, Kang GJ, Yoon WJ, Kang HK, Kim YS, Kim SM, Yoo ES. Anti-inflammatory effect of unripe fruit of Citrus grandis Osbeck in RAW 264.7 and HaCat cells. Korean Journal of Pharmacognosy. 2006. 37: 74-80.

Lim HK, Yoo ES, Moon JY, Jeon YJ, Cho SK. Antioxidant activity of extracts from Dangyuja (Citrus grandis Osbeck) fruits produced in Jeju island. Food Science and Biotechnology. 2006. 15: 312-316

Lim HK, Moon JY, Kim HN, Cho MJ, Cho SK. Induction of apoptosis in U937 human leukemia cells by the hexane fraction of an extract of immature Citrus grandis Osbeck fruits. Food Chemistry. 2009. 114: 1245-1250.

Nieva Moreno MI, Isla MI, Sampietro AR, Vattuone MA. Comparison of the free radical-scavenging activity of propolis from 
several regions of Argentina. Journal of Ethnopharmacology. 2000. 71: 109-114.

Re R, Pellegrini N, Proteggente A, Pannala A, Yang M, RiceEvans C. Antioxidant activity applying an improved ABTS radical cation decolorization assay. Free Radical Biology and Medicine. 1999. 26: 1231-1237.

Song EY, Choi YH, Kang KH, Koh JS. Quality characteristics of citrus fruits according to the harvest date and variety. Agricultural Chemistry and Biotechnology. 1997. 40: 416-421.

Turkmen N, Sari F, Velioglu YS. Effects of extraction solvents on concentration and antioxidant activity of black and black mate tea polyphenols determined by ferrous tartrate and Folin-Ciocalteu methods. Food Chemistry. 2006. 99: 835 $-841$.

https://doi.org/10.15616/BSL.2020.26.2.109

Cite this article as: Lee SG, Lee D, Kang H. Effect of Extraction Ethanol Concentration on Antioxidant and Anti-Inflammatory Activity of 30-Year-Old and 120Year-Old Dangyuja (Citrus maxima (Burm.) Merr.). Biomedical Science Letters. 2020. 26: 109-113. 